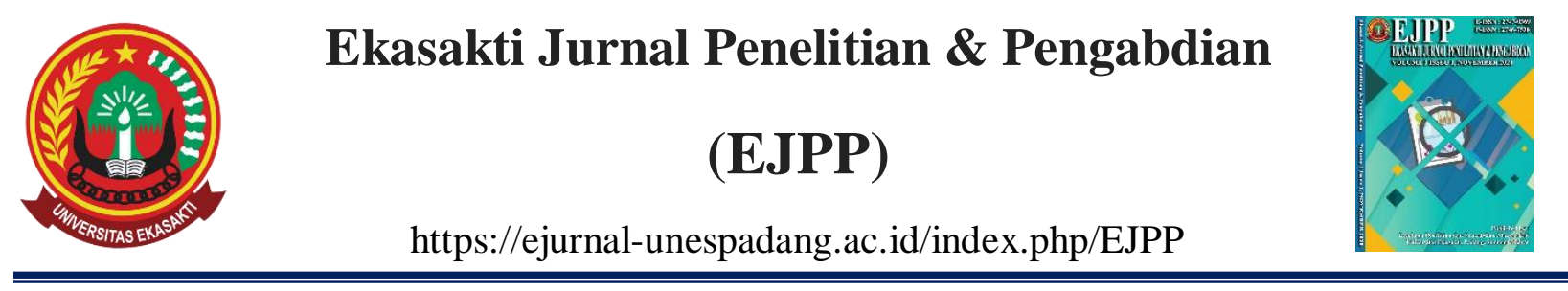

\title{
SOSIALISASI MODEL PEMBELAJARAN CONTEXTUAL TEACHING LEARNING (CTL) DALAM MENINGKATKAN MUTU PENDIDIKAN DI SMA NEGERI 2 SIPORA
}

\author{
Azwar $^{1}$, dan Weni Yulastri ${ }^{2}$ \\ 1) STKIP PGRI, Sumatera Barat. \\ Email: makmurazwar@gmail.com \\ 2) STKIP PGRI, Sumatera Barat. \\ Email: weniyulastri21@gmail.com
}

\section{INFO ARTIKEL}

Received : 29/03/2021

Revised : 20/04/2021

Publish : 01/05/2021

Kata Kunci:

Siswa, Model, CTL, SMA.

\begin{abstract}
ABSTRAK
Keberhasilan guru dan siswa dalam pembelajaran di kelas didukung oleh banyak faktor seperti kompetensi guru, kelengkapan bahan ajar, sarana prasarana dan yang tak kalah penting adalah model pembelajaran. Melalui model pembelajaran guru dan siswa memiliki kerangka konseptual dalam proses pembelajaran dari awal sampai akhir. Dari hasil penelitian selama dua tahun, model yang efektif dan efesien untuk tercapainya tujuan belajar dan hasil belajar yang tepat adalah model pembelajaran Contektual Teaching and Learning (CTL). Model CTL membantu guru dan siswa mengaitkan materi yang diajarkan dengan dunia nyata yang dihadapi siswa, dengan kata lain model CTL ini membangu jembatan antara pengetahuan siswa dengan kehidupan mereka sehari hari dalam keluarga dan masyarakat. Model pembelajaran CTL ini perlu disosialisasikan ke guru dan siswa sehingga layak dijadikan pengabdian pada masyarakat terutama ke sekolah. Setelah melalui beberapa pertimbangan maka sekolah yang dijadikan lokasi adalah SMA 2 Sipora Kab. Kepulauan Mentawai. SMA 2 Sipora berada dekat dengan Ibu Kota Kabupaten yaitu Tua Pejat di pulau Sipora salah satu tiga pulai besar di Kepulauan Mentawai. Dengan sosialisasi model pembelajaran CTL di SMA 2 Sipora dapat menjadi sekolah model untuk mutu pendidikan SMA di kepulauan Mentawai. Kita memahami mutu pembelajaran di SMA ini serta umumnya sekolah di Kepulauan Mentawai masih tertinggal dari daeerah lain di Sumatera Barat. Sosialisasi model pembelajaran CTL kepada siswa di SMA 2 Sipora berupa komponen model CTL yaitu konstuksivisme, inquiry, questioning, learning commbaby, modeling, reflection dan authentic assesment. Kegiatan sosialisasi ini mendapat sambutan meriah dan menjadi pemicu semangat belajar bagi siswa SMA 2 Sipora untuk mengaitkan materi pelajaran dengan dunia nyata mereka, sehingga terasa sekali bagi mereka manfaat belajar di sekolah ketika meraka berada di rumah atau dalam lingkungan tempat tinggal mereka. Sosialisasi ini juga di sambut dengan senang hati oleh kepala sekolah dan guru SMA 2 Sipora, karena pengabdi dan tim datang dengan suka rela dan juga telah berjuang menerjang ombak Samudera Hindia untuk sampai di SMA 2 Sipora.
\end{abstract}


Keywords:

Student, Model, CTL, High School

\section{ABSTRACT}

The success of teachers and students in classroom learning is supported by many factors such as teacher competence, completeness of teaching materials, infrastructure and no less important is the learning model. Through the learning model, teachers and students have a conceptual framework in the learning process from beginning to end. From the results of research for two years, an effective and efficient model for achieving learning objectives and appropriate learning outcomes is the Contextual Teaching and Learning (CTL) learning model. The CTL model helps teachers and students relate the material being taught to the real world faced by students, in other words this CTL model builds a bridge between students' knowledge and their daily lives in their families and communities. This CTL learning model needs to be socialized to teachers and students so that it is worthy of being used as community service, especially to schools. After going through several considerations, the school that was used as the location was SMA 2 Sipora Kab. Mentawai Islands. SMA 2 Sipora is close to the district capital, Tua Pejat, on Sipora Island, one of the three major islands in the Mentawai Islands. By socializing the CTL learning model at SMA 2 Sipora, it can become a model school for the quality of high school education in the Mentawai islands. We understand the quality of learning in this high school and generally schools in the Mentawai Islands are still lagging behind other areas in West Sumatra. The socialization of the CTL learning model to students at SMA 2 Sipora is in the form of components of the CTL model, namely constructivism, inquiry, questioning, learning combo, modeling, reflection and authentic assessment. This socialization activity received a warm welcome and became a trigger for the enthusiasm of learning for SMA 2 Sipora students to relate the subject matter to their real world, so that they felt the benefits of studying at school when they were at home or in their neighborhood. This socialization was also warmly welcomed by the principal and teachers of SMA 2 Sipora, because the devotees and team came voluntarily and had also struggled to brave the waves of the Indian Ocean to reach SMA 2 Sipora.

\section{DOI: https://doi.org/10.31933/ejpp.v1i2.353}

\section{PENDAHULUAN}

Guru memiliki peranan yang sangat penting dalam hal menumbuhkembangkan minat siswa untuk meraih prestasi dalam bidang pelajaran. Untuk itu seorang guru perlu mencari strategi alternatif dalam menumbuhkan minat siswa agar mau belajar dengan gembira (tanpa merasa dipaksa), sehingga dapat menimbulkan percaya diri pada siswa, yang pada akhirnya mereka dapat mengembangkan kemampuan yang telah ada tanpa mereka sadari.

Jika dilihat secara khusus, dari berbagai harapan dalam proses pembelajaran di sekolah, khususnya tingkat SMA, model pembelajaran yang digunakan guru biasanya adalah model konvensional, di mana guru menerangkan lalu siswa mencatat. Di sini, siswa sama sekali tidak bisa mengaplikasikan ilmu yang diperoleh. Belum optimalnya guru menerapkan model pembelajaran dapat mengakibatkan proses pembelajaran yang kurang bermakna, siswa tidak aktif, siswa tidak dibiasakan berpikir kritis dan meningkatkan penalaran dalam memecahkan suatu masalah. Dengan demikian, guru dituntut untuk berusaha keras dengan bersungguh- 
sungguh menemukan kaidah/cara yang tepat bagaimana proses pendidikan dapat menjadi ladang tumbuh kembangnya karakter.

Problem lain yang juga menjadi tantangan bisa menjadi indikasi ketidakefektifan proses pembelajaran adalah ketidaktersediaan strategi penyusunan dan pemilihan materi-materi sehingga sering tidak ditemukan hal-hal yang prinsipil. Dengan demikian, pencarian format yang tepat dan efektif dalam proses pembelajaran itulah yang dinamakan dengan model pembelajaran, yang dapat disebut juga sebagai sebagai kerangka konseptual dalam pembelajaran mulia dari awal sampai akhir pembelajaran. Hal ini sesuai dengan pendapat Syukri Fathudin (2008) yang menyatakan bahwa diperlukan upaya strategis dan sistematis dalam mencari model pembelajaran yang efektif dalam membangun perilaku baik siswa. Salah satu model yang tepat digunakan untuk tujuan di atas adalah model pembelajaran Contextual Teaching Learning (CTL). Pilihan Model ini dianggap efektif karena mendorong siswa untuk berprestasi sehingga mampu meningkatkan mutu pendidikan. Pendekatan kontekstual dalam pembelajaran kontekstual (Contextual Teaching and Learning) disingkat menjadi CTL merupakan konsep belajar yang membantu guru mengaitkan antara materi yang diajarkannya dengan situasi dunia nyata siswa dan mendorong siswa membuat hubungan antara pengetahuan yang dimilikinya dengan penerapannya dalam kehidupan mereka sebagai anggota keluarga dan masyarakat.

Model pembelajaran Contextual Teaching and Learning (CTL), menawarkan bentuk pembelajaran yang membantu guru mengaitkan antara materi yang diajarkan dengan situasi dunia nyata siswa. Depdiknas (2003), Sanjaya (2006), dan Trianto (2007) dalam Rostiawati dan Maulana, 2008 menyimpulkan bahwa CTL merupakan suatu pendekatan pembelajaran yang menekankan pada proses keterlibatan siswa untuk menemukan materi yang dipelajarinya dan menghubungkan serta menerapkannya dalam kehidupan mereka. Dengan demikian, peran siswa dalam pembelajaran CTL adalah sebagai subjek pembelajar yang menemukan dan membangun sendiri konsep-konsep yang dipelajarinya. Belajar bukanlah menghafal dan mengingat faktafakta, tetapi belajar adalah upaya untuk mengoptimalkan potensi siswa baik aspek kognitif, afektif, maupun psikomotor.

Mengingat pentingnya materi ini, maka diperlukan adanya sosialisasi kepada siswa mengenai model pembelajaran CTL dalam proses pembelajaran. Pelatihan dan penyuluhan yang dilakukan ini merupakan aplikasi dari kegiatan pengabdian masyarakat yang merupakan salah satu dari Tri Darma Perguruan Tinggi, selain dari pelaksanaan pendidikan dan penelitian. Khusus mengenai pengabdian pada masyarakat, kegiatan ini ditujukan sebagai instrument dan cara kerja untuk memecahkan masalah kemasyarakatan secara ilmiah. Hal ini bermakna bahwa kegiatan pengabdian kepada masyarakat merupakan wahana penerapan ilmu dan keahlian civitas akademika dalam konteks kehidupan bermasyarakat.

Persoalan mitra: Selama ini, akibat guru yang selalu menggunakan model pembelajaran konvesional, maka siswa tidak tahu, tidak faham, dan tidak mengerti dengan model pembelajaran lain yang dapat digunakan dalam proses pembelajaran. Oleh karena itu, untuk meningkatkan mutu pendidikan, maka tim pelaksana pengabdian pada masyarakat ini akan memberikan 
sosialisasi kepada siswa mengenai model pembelajaran CTL yang dapat meningkatkan mutu pendidikan.

Solusi yang ditawarkan agar siswa memahami mengenai model pembelajaran CTL adalah dengan memberikan sosialisasi dan workshop kepada siswa SMA Negeri 2 Sipora agar mereka tahu dan faham mengenai model ini dan kemudian jika guru menggunakan model ini dalam proses pembelajaran, mereka sudah tahu dan tidak lagi merasa asing dengan model yang dimaksud.

Target dan Luaran berupa model pembelajaran CTL dengan memberikan sosialisasi dan workshop kepada siswa SMA Negeri 2 Sipora agar mereka tahu dan faham mengenai model ini dan kemudian jika guru menggunakan model ini dalam proses pembelajaran, mereka sudah tahu dan tidak lagi merasa asing dengan model yang dimaksud.

Berdasarkan uraian pada análisis situasi yang telah dikemukakan, maka kegiatan ini perlu dibatasi sebagai berikut:

1. Kegiatan pengabdian pada masyarakat ini dilaksanakan di SMA Negeri 2 Sipora.

2. Tema kegiatan ini adalah "Sosialisasi Model Pembelajaran Contextual Teaching Learning (CTL) dalam Meningkatkan Mutu Pendidikan di SMA Negeri 2 Sipora".

3. Kegiatan ini akan mengenalkan kepada siswa tentang model pembelajaran CTL

4. Kegiatan ini dilaksanakan selama 1 bulan.

Berdasarkan batasan kegiatan yang telah dikemukakan di atas, maka kegiatan ini dirumuskan sebagai berikut:

a. Bagaiamana pelaksanaan kegiatan pengabdian pada masyarakat yang dilakukan di SMA Negeri 2 Sipora?

b. Bagaimana tingkat keberhasilan dalam pelaksanaan kegiatan kegiatan pengabdian pada masyarakat yang dilakukan di SMA Negeri 2 Sipora?

\section{METODE PENELITIAN}

Metode pelaksanaan kegiatan ini dilakukan untuk memberikan solusi dalam rangka mengatasi permasalahn mitra. Pendekatan yang digunakan adalah pendekatan yang bersifat bersifat "bottom up", dimana perencanaan tindakan diupayakan menjawab permasalahan dan kebutuhan mitra dan dilakukan secara intensif dan partisipatif. Tahapan yang dilakukan secara umum adalah sebagai berikut:

1. Analisis kebutuhan

Menganalisis kebutuhan mitra untuk mencari solusi dari permasalahan.

2. Rencana kerja

Setelah menganalisis kebutuhan mitra, pelaksana membuat rencana kerja atau kegiatan yang akan diterapkan. Rencana kerja meliputi: persiapan kegiatan, pelaksanaan kegiatan, monitoring dan evaluasi kegiatan.

3. Pelaksanaan kegiatan

Pelaksanaan kegiatan meliputi pelaksanaan pemberian pelatihan dan workshop di lokasi mitra yang sesuai dengan rencana kerja yang telah disusun. 
4. Evaluasi untuk semua program kegiatan dan mengevaluasinya sesuai target luaran. Dengan demikian, dapat dikatakan bahwa kegiatan ini berupa pemberian materi intensif dan workshop kepada peserta.

\section{HASIL DAN PEMBAHASAN}

\section{Gambaraan Lokasi Mitra}

Kegiatan pengabdian pada masyarakat ini dilakukan di Sekolah Menengah Atas (SMA) Negeri 2 Sipora. Sipora merupakan salah satu kecamatan dalam wilayah Kabupaten Kepulauan Mentawai, tepatnya terletak di Pulau Sipora, satu dari tiga gugusan pulau besar di kabupaten tersebut.

SMA Negeri 2 Sipora merupakan salah satu sekolah menengah atas negeri yang ada di Kabupaten Kepulauan Mentawai, tepatnya terletak di Tua Pejat, Desa/Keluarahan Sipo ra Jaya, Kecamatan Sipora Utara. Sama dengan SMA pada umumnya di Indonesia, masa pendidikan sekolah di SMA N 1 Pagai Utara Selatan ditempuh dalam waktu 3 tahun pelajaran, mulai dari kelas X sampai dengan kelas XII, dengan jurusan yang terbagi menjadi IPA dan IPS.

Saat ini, SMA N 2 Sipora dipimpin oleh bapak Bisronel,S.Pd., sebagai kepala sekolah. Jumlah keseluruhan guru adalah 48 orang guru dengan jumlah siswa sebanyak 553 orang siswa, yang terdiri daro 273 orang siswa laki-laki dan 280 orang siswa perempuan. Sementara itu, jumlah rombongan belajar (rombel) secara keseluruhan adalah berjumlah 21 rombel. Berbagai fasilitas dimiliki oleh SMA N Sipora untuk menunjang kegiatan belajar mengajat. Fasilitas tersebut antara lain: Ruang kelas sebanyak 24 kelas, Ruang majelis guru, Perpustakaan, dan Laboratorium 2 buah.

Di SMA N 2 Sipora memiliki banyak kegiatan ekstra kurikuler, diantaranya pramuka, dan kegiatan lainnya. Latar belakang anak-anak yang sekolah di SMA N 2 Sipora rata-rata adalah anak yang berdomisili di wilayah setempat/warga pribumi. Akses untuk mencapai sekolah ini dapat dilakukan melalui jalur darat.

\section{Pelaksanaan Kegiatan}

Kegiatan pengabdian pada masyarakat ini dilaksanakan pada selama 1 bulan, yaitu pada pada tanggal 10 September 2018 s/d 10 Oktober 2018. Materi yang diberikan adalah memperkenalkan serta memberi sosialisasi mengenai Model Pembelajaran Contextual Teaching Learning (CTL) dalam Meningkatkan Mutu Pendidikan di SMA Negeri 2 Sipora. Metode Ceramah dilakukan dengan memberikan penjelasan tentang karakter. Pada metode kedua yaitu diskusi dilakukan dengan memberikan waktu bila ada pertanyaan atau tanggapan dari peserta. Peserta kegiatan adalah siswa kelas X dengan jumlah 25 orang. Materi ini diberikan oleh Bapak Azwar, M.HI. Berikut uraian materi yang diberikan:

1. Model Pembelajaran

Menurut Supriyono (2003:60), sebuah model pembelajaran adalah sebuah rencana atau pola yang mengorganisasi pembelajaran dalam kelas dan menunjukkan carapenggunaan materi peembelajaran. Pendapat lain mengatakan bahwa model 
pembelajaran adalah cara-cara atau teknik penyajian bahan ajaran yang akan digunakan oleh guru pada saat menyajikan bahan pelajaran, bak secara individual maupun secara kelompok.

Sementara Joyce dan Weil (1996:7) mengatakan bahwa model pembelajaran adalah deskripsi dari lingkungan pembelajaran yang bergerak dari perencanaan kurikulum, mata pelajaran, bagian-bagian dari pelajaran untuk merangcang materi pelajaran, buku latihan kerja, program, dan bantuan kompetensi untuk program pembelajaran. Dengan kata lain, model pembelajaran adalah bantuan alat-alat yang mempermudah siswa dalam belajar. Jadi, keberadaan model pembelajaran berfungsi membantu siswa memperoleh informasi, gagasan, keterampilan, nilai- nilai, cara berpikir dan pengertian yang diekspresikan mereka. (Syafaruddin, Irwan Nasution, 2005: 182183)

Model pembelajaran yang tepat adalah model pembelajaran yang diterapkan pada pembelajaran bahan kajian atau pokok bahasan atau sub pokok bahasan tertentu dengan menggunakan waktu, dana tak begitu banyak dan mendapatkan hasil yang dapat diserap siswa secara maksimal.

2. Model Pembelajaran Contextual Teaching Learning (CTL)

Menurut Nurhadi dalam Sugiyanto (2007) Contextual Teaching Learning (CTL) adalah konsep belajar yang mendorong guru untuk menghubungkan antara materi yang diajarkan dan situasi dunia nyata siswa. Semnetara menurut Jonhson dalam Sugiyanto (2007) CTL adalah sebuah proses pendidikan yang bertujuan untuk menolong para siswa melihat siswa melihat makna didalam materi akademik yang mereka pelajari dengan cara menghubungkan subyek-subyek akademik dengan konteks dalam kehidupan keseharian mereka.

Berdasarkan pendapat para ahli di atas, maka dapat disimpulkan bahwa CTL adalah konsep belajar yang membantu guru mengkaitkan antara materi yang diajarkanya dengan situasi dunia nyata siswa dan mendorong siswa membuat hubungan antara pengetahuan yang dimilikinya dengan penerapan dalam kehidupan sehari-hari. Adapun tujuan dari model CTL ini adalah:

a. Model pembelajaran CTL ini bertujuan untuk memotivasi siswa untuk memahami makna materi pelajaran yang dipelajarinya dengan mengkaitkan materi tersebut dengan konteks kehidupan mereka sehari-hari sehingga siswa memiliki pengetahuan atu ketrampilan yang secara refleksi dapat diterapkan dari permasalahan kepermasalahan lainya.

b. Model pembelajaran ini bertujuan agar dalam belajar itu tidak hanya sekedar menghafal tetapi perlu dengan adanya pemahaman.

c. Model pembelajaran ini menekankan pada pengembangan minat pengalaman siswa.

d. Model pembelajaran CTL ini bertujuan untuk melatih siswa agar dapat berpikir kritis dan terampil dalam memproses pengetahuan agar dapat menemukan dan menciptakan sesuatu yang bermanfaat bagi dirinya sendiri dan orang lain. 
e. Model pembelajaran CTL ini bertujun agar pembelajaran lebih produktif dan bermakna.

f. Model pembelajaran model CTL ini bertujuan untuk mengajak anak pada suatu aktivitas yang mengkaitkan materi akademik dengan konteks kehidupan sehari-hari.

g. Tujuan pembelajaran model CTL ini bertujuan agar siswa secara individu dapat menemukan dan mentrasfer informasi-informasi komplek dan siswa dapat menjadikan informasi itu miliknya sendiri.

\section{Keberhasilan}

Kegiatan ini bisa dikatakan telah mencapai target yang ditetapkan. Siswa sebagai peserta kegiatan telah memiliki pemahaman, pengetahuan, dan wawasan mengenai model pembelajaran CTL. Siswa terlihat sangat antusias dalam mengikuti kegiatan yang diadakan ini. Bahkan sebagian besar siswa terlihat memberikan pertanyaan kepada tim pelaksana kegiatan/narasumber mengenai materi yang diberikan.

\section{Evaluasi}

Untuk mengetahui tingkat ketercapaian tujuan pelatihan dilakukan dengan evaluasi. Evaluasi dilakukan bersamaan dengan proses pelatihan, artinya setiap peserta yang mengikuti pelatihan dipantau oleh 4 orang anggota tim pelaksana, yang langsung dibimbing apabila mengalami kesulitan.

Pada proses pelatihan peserta diberi penjelasan awal, kemudian dibimbing untuk memahami materi yang diberikan. Apabila ada bagian yang belum dipahami oleh peserta, instruktur wajib menerangkan kembali sehingga peserta betul-betul paham mengenaimodel pembelajaran CTL.

\section{KESIMPULAN}

Kesimpulan yang dapat diambil dalam penulisan laporan pengbdian pada masyarakat ini adalah:

1. Tim P3M dari STKIP PGRI Sumatera Barat telah berhasil melaksanakan program pengabdian pada masyarakat di SMA N 2 Sipora, Kabupaten Kepulauan Mentawai.

2. Sekolah sangat mendukung terlaksananya program ini.

3. Siswa sebagai peserta pelatihan sangat antusias mengikuti kegiatan ini dilihat dari respon dan jumlah peserta saat pelatihan.

4. Terjalin kemitraan dan kerjasama antara pihak STKIP PGRI Sumatera barat dan SMA N 2 Siporaw.

\section{REFERENSI}

Alwasilah, Chaedar. 2006. Contextual Teaching and Learning. Departemen Pendidikan Nasional. Jakarta. 
Asma, Nur. 2006. Model Pembelajaran Kooperatif. Departemen Pendidikan Nasional. Jakarta. Lickona, Thomas. 2014. Educating For Character: Journal of Moral Education. 